\title{
ANALISIS SINYAL WIRELESS BERDASARKAN JARAK ANTAR ACCESS POINT MENGGUNAKAN METODE SIMULATED ANNEALING PADA SMAN 1 PRAYA TENGAH
}

\author{
Moh. Husni Taufik ${ }^{1}$, Mohammad Fauzi Zulkarnain ${ }^{2}$, Maemun Saleh ${ }^{3}$ \\ Teknik Informatika, STMIK Lombok \\ Jln. Basuki Rahmat No. 105. Praya Lombok Tengah 83511 \\ ${ }^{1}$ taufik_mohammad88@yahoo.com, ${ }^{2}$ fauzi tuan@yahoo.com, ${ }^{3}$ saleh16semb@gmail.com
}

\begin{abstract}
Access point placement on wireless networks is needed to optimize the strength of signal received by receiver from transmitter. The most influential parameter in determining the performance of access point position is signal strenght, because this value will be used to determine the coverage area of a access point. In this research, signal strengths of access point to receiver in the SMAN 1 Praya Tengah have been measured using inSSIDer application and results in the values of RSSI from transmitter to receiver. Data obtained from the filed measurements are used to analyse the influence of access point placement using simulate annealing. The research conducted is expected to generate an appropriate position and analysis for further optimization of access point position on wireless network.
\end{abstract}

Keywords: Wireless, Coverage Area, RSSI, Propagation, Simulated Annealing

\section{Pendahuluan}

Penempatan posisi access point yang tepat sangat diperlukan untuk mengoptimalkan kekuatan sinyal yang diterima dari pengirim dan penerima. Ada cara praktis yang dapat dilakukan untuk menempatkan posisi access point yakni di tengah-tengah ruangan atau lokasi, namun terkadang hal ini tidak dapat dilakukan karena dalam perencanaan pengembangan, tidak hanya sekedar memasang infrastruktur perangkat access point, tetapi juga harus memperhatikan beragam faktor antara lain kekuatan daya pancar sinyal access point, desain dan infrastruktur perangkat access point, desain dan infrastruktur ruangan, sebaran pengguna access point yang berkelompok, terjadinya interferensi gelombang radio, hambatan sinyal seperti frekuensi radio, dan penghalang yang dapat menimbulkan gangguan terhadap penerimaan sinyal dari access point (transmitter) terhadap perangkat penerima (receiver) dimana posisi access point sangat berpengaruh terhadap area jangkauan untuk penerima pada sebuah jaringan nirkabel (tanpa kabel) . Semakin optimal penempatan posisi access point, semakin optimal juga area jangkauan untuk penerima.

Menempatkan posisi access point dengan cara manual tentunya akan dibutuhkan tenaga yang lebih untuk melakukan survey pengukuran dilapangan, waktu yang lama dan biaya yang tidak murah. Untuk itu dibutuhkan penanganan dan mekanisme yang baik dalam meminimalisir tenaga, biaya dan waktu dalam menempatkan access point untuk mendapatkan hasil yang optimal serta dapat menentukan jumlah access point yang ideal untuk suatu lokasi dengan berbagai ukuran yang ada serta dapat ditentukan melalui perhitungan tanpa melakukan survey lapangan yang aktual.

Oleh karena itu, sebuah pendekatan alternatif yang diusulkan adalah melakukan pengujian menggunakan perangkat lunak menggunakan metode optimasi yang memberikan solusi yang lebih bagus tanpa melebihi batasan waktu yang disediakan. Metode optimasi yang akan digunakan pada penelitian ini adalah Simulated annealing yang merupakan metode optimasi yang mensimulasikan proses annealing pada penempatan posisi access point untuk menghasilkan area jangkauan yang optimal dengan menggunakan energi seminimal mungkin.

\section{Metodologi Penelitian}

\subsection{Metodologi Pengumpulan Data}

1. Studi Kepustakaan

Peneliti mendapatkan pengetahuan dengan membaca literature seperti artikel, jurnal dan lain-lain yang berkaitan dengan analisis sinyal wireless berdasarkan jarak antar access point menggunakan metode Simulated annealing. 


\section{Pengambilan Data Dengan Skenario Pengukuran}

1. Teknik pengambilan data dilakukan dengan mengambil informasi tentang RSSI (Receive Signal Strength Indicator) menggunakan aplikasi InSSIDER dari pemancar (access point) ke penerima (Notebook) sesuai dengan jarak titik pengambilan sample pengukuran;

2. Kriteria pengukuran meliputi tinggi transmitter dan jenis propagasi lintasan yaitu propagasi LOS (Line Of Sight) dan NLOS (Non Line Of Sight);

3. Dalam pengukuran, terdapat parameter yang diamati antara lain RSSI yang menunjukkan variasi yang besar karena adanya pengaruh dari jarak koordinat yang diukur;

4. Mengukur jarak jangkauan sinyal wireless.

\subsection{Metode Analisis dan Pengembangan}

Pada tahap ini akan dibuat gambaran awal posisi access point. Selanjutnya akan dilakukan pengujian berdasarkan jarak antar access point dan posisi access point. Melakukan perhitungan parameter-parameter yang dicari untuk menentukan area jangkauan maksimum berdasarkan pada fungsi jarak, pengaruh tinggi transmitter terhadap nilai RSSI.

\subsection{Metode Pengujian}

Pada tahap ini, akan dilakukan pengujian terhadap hasil analisa sistem yaitu: Melakukan analisa ulang terhadap jangkauan access point dengan mengukur nilai RSSI dari eksperimen yang telah dilakukan terhadap posisi access point. Hal ini bertujuan untuk mengetahui sejauh mana ketepatan eksekusi sistem yang telah dibuat, sehingga tidak menutup kemungkinan dapat mengetahui kelemahannya.

\section{Tinjauan Pustaka}

Menurut Nila Feby Puspitasari (2014) dalam Jurnalnya "Optimasi Penempatan Posisi Access Point pada Jaringan Wi-Fi Menggunakan Metode Simulated Annealing". Dari hasil yang didapatkan bahwa : Metode yang dikembangkan dalam penelitian ini memberikan hasil optimisasi yang lebih baik dibandingkan dengan perencanaan awal. Berdasarkan hasil pengujian dengan pemodelan sistem menggunakan metode simulated annealing dengan nilai threshold level daya sebesar -30dBM, menunjukkan bahwa penempatan tinggi access point pada ketinggian $120 \mathrm{~cm}$ dan ketinggian $230 \mathrm{~cm}$ pada propagasi LOS untuk lingkungan ruang dosen gedung 2 lantai 1 STMIK AMIKOM Yogyakarta menghasilkan presentase coverage area terbaik yang sama yaitu sebesar $98.66 \%$.

\section{Analisa Dan Perancangan \\ 4.1 Analisis (Analysis) \\ 1. Bahan Pengembangan}

Bahan yang digunakan dalam pengembangan sistem jaringan ini adalah sebagai berikut:

1. Data primer, mencakup data yang diambil dari studi-studi literatur yang dilakukan pada proses pengembangan.

2. Data sekunder, merupakan data yang diambil secara langsung melalui wawancara, sitesurvey dan data pengukuran langsung peralatan jaringan wireless yang ada.

\section{Alat Pengembangan}

Alat yang digunakan dalam pengembangan ini adalah sebagi berikut:

1. Software

1) Inssider Home edition, untuk melakukan sitesurvey yaitu mengetahui kondisi lapangan mengenai keberadaan perangkat wireless (AP) yang ada pada jaringan.

2) Microsoft Office Visio, software yang digunakan untuk menggambarkan desain arsitektur jaringan.

2. Hardware

1) Satu buah access point TP-Link TLWA7210N (outdoor) beserta perlengkapannya.

2) Dua buah access point/ router TP-Link TL-WRD3600 (indoor) beserta perlengkapannya.

3) Mikrotik Router Board.

4) Kabel UTP.

5) Meteran.

6) Konektor RJ 45.

7) Tang Krimping.

8) Komputer laptop untuk menjalankan Inssider.

\subsection{Tahap Pengembangan}

Langkah-langkah pengembangan yang dilakukan adalah sebagai berikut:

1. Investigasi Awal

Tahap ini dilakukan untuk memperoleh data yang akan digunakan dalam melakukan perencanaan jaringan

1) Melakukan identifikasi aplikasi dan layanan yang akan digunakan oleh pengguna jaringan.

2) Melakukan identifikasi jaringan terdahulu. Identifikasi ini bertujuan untuk mengetahui hal-hal yang masih perlu dan dapat dipertahankan dari jaringan yang telah ada.

2. Analisa Kebutuhan.

Analisa kebutuhan ini dilakukan untuk mendapatkan gambaran kebutuhan dari jaringan yang direncanakan dan solusi yang bisa diberikan. Adapun langkah-langkah yang dilakukan pada tahap ini adalah sebagai berikut: 
1) Gap analysis, dilakukan untuk memberikan gambaran mengenai penambahan fitur dan layanan yang harus dilakukan dalam jaringan yang akan dikembangkan berdasarkan identifikasi jaringan terdahulu.

2) Identifikasi kebutuhan teknologi yang akan digunakan untuk membangun jaringan.

Adapun langkah-langkah penelitian yang telah disebutkan di atas dapat ditunjukkan pada gambar 4.1 di bawah ini:

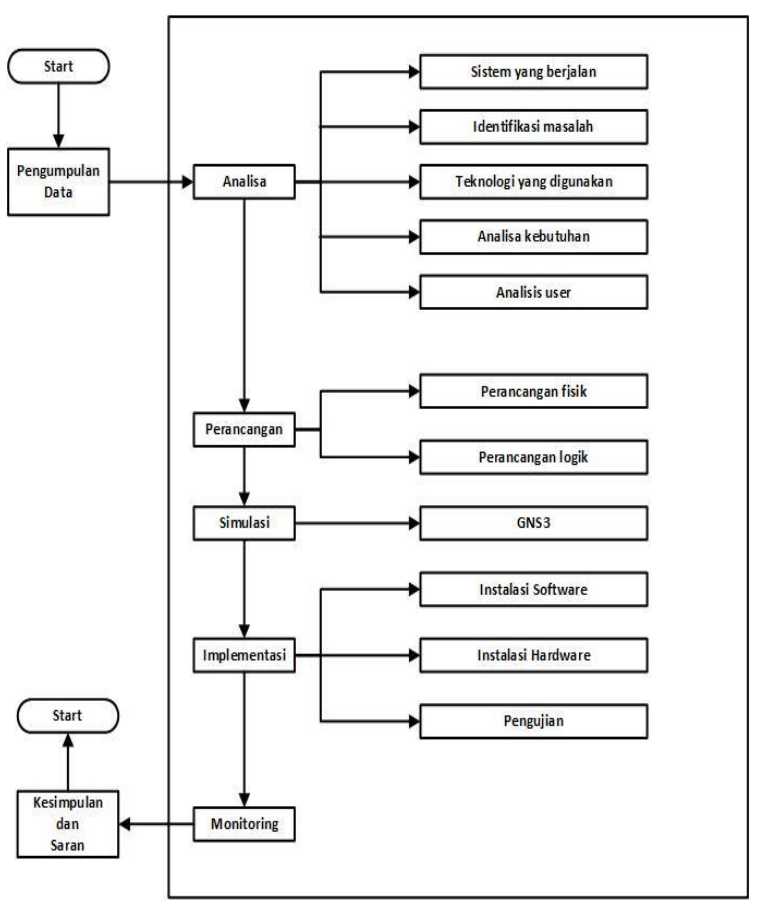

Gambar 4.1 Diagram Alir Pengembangan

\section{Implementasi Dan Pembahasan \\ 5.1 Investigasi Awal}

Berdasarkan dari hasil investigasi, dilakukan untuk mendapatkan informasi jaringan komputer yang ada pada SMAN 1 Praya tengah telah ada untuk digunakan dalam melakukan analisa sinyal wireless.

\subsection{Kebutuhan Layanan}

Untuk memenuhi kebutuhan (staf, guru dan siswa) dan pengembangan jaringan, maka dapat dijabarkan beberapa layanan atau fasilitas jaringan diantaranya sebagai berikut:

1. Akses Internet

Jaringan yang dikembangkan bisa memberikan layanan akses antar sesama sehingga dapat berbagi data (sharing file), dan hubungan antar pengguna lainnya.

2. Hotspot

Selain memiliki pengguna yang berkedudukan tetap (fixed) di masingmasing ruang, pengguna jaringan juga harus dapat mengakses internet di semua area dengan leluasa.
3. Keamanan

Jaringan wireless dikenal memiliki kemampuan proteksi keamanan yang lebih lemah dari jaringan yang lainnya, jaringan diharapkan dapat mencegah penyalahgunaan otoritas kehilangan dan manipulasi data.

4. Pengelolaan

Semakin luasnya jaringan dan banyaknya jumlah pengguna (staf, guru dan siswa) menyebabkan pengaturan yang lebih kompleks dan membutuhkan layanan yang bisa mengatur tentang autentikasi, autorisasi dan akunting dalam akses terhadap jaringan.

5. Pengembangan

Semakin tingginya tingkat perkembangan kebutuhan akan teknologi dan informasi serta luas wilayah yang cukup luas membuat jaringan yang ada dituntut untuk dikembangkan.

\subsection{CoverageArea (Area Cakupan)}

Besar coverage area atau area cakupan dari wireless access point diperlukan untuk mengetahui luas cakupan dan jumlah access point yang diperlukan dalam pengembangan jaringan komputer SMAN 1 Praya Tengah untuk mencapai hasil yang diinginkan.

Harus didapatkan sekitar 10 - 15 dB SOM pada sistem penerima dan mengirim untuk mengatasi terjadinya multipath dan fading, sehingga sistem dapat dipastikan berjalan dengan baik. Jika persyaratan lain untuk terpenuhinya hubungan yang baik seperti line-of-sight, cuaca, dan FZC terpenuhi, maka

1.CoverageArea Untuk Perangkat Jaringan Backbone

1. Dengan spesifikasi umum peralatan access point yang sama baik penerima dan pengirim pada jaringan backbone (TPLink TL-WA7210N) yaitu:

Txpower $\quad: 27 \mathrm{dBm}$

Receiver sencitivity : :-76 dBm (150 Mbps)

Tx \& Rx antenna gain : $12 \mathrm{dBi}$

Tx cable \& Conn. $\quad: 0 \mathrm{dBm}$

Rx cable \& Conn. $\quad: 0 \mathrm{dBm}$

\subsection{Radio Link Calculation dan Daya Pancar.}

Radio link calculation atau link budget dilakukan untuk memastikan stasiun penerima memperoleh kuat sinyal (daya pancar) yang cukup untuk membangun sebuah hubungan. Parameter-parameter yang mempengaruhi besarnya kualitas penerimaan daya sebuah stasiun penerima adalah daya pancar peralatan radio pemancar (Tx Power), pennguatan antena pemancar ( $T x$ antena gain), hilangnya daya akibat kabel dan konektor pada penerima maupun pemancar, penguatan antena penerima ( $R x$ antena gain),dan jarak antar stasiun penerima dan pemancar yang disebut free space loss (FSL) (Tesis Agus Arimbawa , 2011:102-103). Perhitungan SOM terdapat banyak parameter input, namun secara umum dapat dibagi tiga, yaitu: 
1. Free Space Loss/FSL (dBi)

2. Received Signal Level (dBm)

3. System Operating Margin (SOM) teoritis

Harus didapatkan 10-15 dB SOM pada

sistem penerima dan pemancar untuk mengatasi terjadinya multipath dan fading, sehingga sistem dapat dipastikan berjalan dengan baik. Untuk menghitung data-data ketiga parameter di atas, maka kita harus menyediakan data-data berikut:

Frekuensi yang dipakai dalam sistem (MHz)

Jarak antar pemancar dan penerima

Tx Power $(\mathrm{dBm})$ dari perangkat wireless

Rx Cable Loss (dBm)

Tx Antenna Gain (dBi)

Rx Antenna Gain (dBi)

Rx Antenna Loss (dBm) receiver

$R x$ Sencitivity atau sensitivitas penerimaan oleh:

Formula punuk menghitung SOM diberikan

SOM = Rx sigma level - Rx sencitivity

$R x$ signal level adalah kuat sinyal yang diterima pada sisi receiver, sedangkan formula untuk menghitung Rx sigma level diberikan oleh:

FSL $=32,45+20 \log \mathrm{D}(\mathrm{Km})+20 \log \mathrm{f}(\mathrm{MHz})$

$\mathrm{Rx}$ sigma level $=\mathrm{Tx}$ Power $-\mathrm{Tx}$ cabe loss $+\mathrm{Tx}$ antenna gain - FSL + Rx antenna ain - Rx cabe loss

Nilai SOM yang diberikan perangkat TPLink TL-WA7210N terhadap penerima dan pengirim.

Berdasarkan hasil pengukuran jarak antara perangkat access point jaringan backbone pada aplikasi inssider, ditentukan jarak terjauh perangkat access point TP-Link TL-WA7210N (pengirim dan penerima) adalah \pm 95 meter $(0,095 \mathrm{Km})$, besar Tx Power minimim perangkat $13 \mathrm{dBm}, \mathrm{Rx}$ sencitivity $-76 \mathrm{dBm}, \mathrm{Tx}$ dan $\mathrm{Rx}$ antenna ain $12 \mathrm{dBi}$, maka nilai FSL dapat ditentukan sebagai berikut:

FSL $=32,45+20 \log \mathrm{D}(\mathrm{KM})+20 \log \mathrm{f}(\mathrm{MHz})$

$\mathrm{FSL}=32,45+20 \log 0,095+20 \log 2400$

FSL $=32,45+(-20,445)+67,604$

FSL $=79,608 \mathrm{~dB}$

RSL dapat ditentukan sebagai berikut:

RSL = Tx Power - Tx cabe loss + Tx antenna gain - FSL + Rx antenna gain - Rx cabe los

RSL $=13-0+12-79,608+12-0$

RSL $=-42,608 \mathrm{dBm}$

Dengan mengetahui RSL, maka SOM dapat ditentukan sebagai berikut:

SOM $=$ RSL - Rx sencitivity

SOM $=-42,608-(-76)$

$\mathrm{SOM}=33,392 \mathrm{dBm}$

Nilai SOM sebesar $33,392 \mathrm{dBm}$ sangat memenuhi syarat yang telah ditetapkan lebih besar dari $10 \mathrm{dBm}$.

\section{Kesimpulan Dan Saran \\ 6.1 Kesimpulan}

Berdasarkan hasil dari pembahasan diperoleh beberapa kesimpulan, diantaranya:

1. Penghubung jaringan antar gedung SMAN 1 Praya Tengah dilakukan menggunakan media wireless, yaitu dengan memanfaatkan beberapa perangkat access point pemancar/pengirim dan beberapa perangkat access point penerima.

2. Jarak jangkauan dari perangkat access pointoutdoor TP-Link TL-WA7210N dengan Tx Power maksimum $27 \mathrm{dBm}$. Jarak jangkauan dari perangkat access point outdoor TP-Link TL-WA7210N dengan Tx Power minimum $(13$ $\mathrm{dBm})$ pada jaringan backbone adalah 789 meter. Dan jarak jangkauan perangkat access point indoor TP-Link TL-WDR3600 pada jaringan akses dengan asumsi tanpa hambatan (Free space loss) adalah 35 meter (diameter 70 meter).

\subsection{Saran}

Saran yang dapat disampaikan berdasarkan penelitian yang telah dilakukan, diantaranya adalah sebagai berikut:

1. Dibutuhkan administrator jaringan yang akan bertugas untuk mengontrol sistem jaringan yang berjalan.

2. Perlunya dilakukan pemeliharaan (maintenance) rutin pada perangkat jaringan, seperti melakukan restart perangkat access point, restart perangkat server(Mikrotik Router Board), dll.

3. Semakin banyaknya pengujian yang dilakukan, maka akan mendapatkan kemungkinan hasil yang lebih baik terhadap hasil optimisasi sebelumnya.

\section{Daftar Pustaka}

Arifin. H. 2011. Kitab Suci Jaringan Komputer dan Koneksi Internet.Yogyakarta.MediaKom.

Arimbawa. I. W. A. 2011. Tesis WMN (Wireless Mesh Network) Berbasis IEEE 802.11B/G Sebagai Solusi Nirkabel Jaringan Komunitas Sebuah Kompleks Perumahan.Teknik Elektro dan Teknologi Informasi Universitas Gadjah Mada.

Baskoro, Alexander Pandu. 2011. Analisis dan Perancangan Jaringan Komputer Studi Kasus : Inna Garuda Yogyakarta. Yogyakarta: Program Studi Teknik Informatika Fakultas Teknologi Industri Universitas Atma Jaya Yogyakarta.

Hasan, Choirus. 2011. Membangun Jaringan Hotspot Wi-Fi RT/RW Net di Kelurahan Belimbing Kecamatan Murung Pudak Kabupaten Tabalong Kalimantan Selatan. Yogyakarta: Jurusan Teknik Informatika STMIK AMIKOM Yogyakarta.

Haris, Lalu Erwin, and Ahmad Susan Pardiansyah. "Aplikasi Android Kamus Bahasa Indonesia- 
Sasak." Jurnal Manajemen Informatika dan Sistem Informasi 1.1 (2018): 1-5.

Maryono Dwi. (2012). Teknologi Informasi dan Komunikasi. P.T. Tiga Serangkai Pustaka Mandiri : Diset dengan Powermac G5

Optimasi Penempatan Posisi Access Point pada Jaringan Wi-Fi Menggunakan Metode Simulated Annealing, http://citec.amikom.ac.id/main/index.php/c itec/article/download/37/37, tanggal akses 31 Agustus 2016.

Optimasi Single Frequency Network pada Layanan TV Digital DVB-T dengan Menggunakan Metode Simulated Annealing, http://www.ejurnal.its.ac.id/index.php/tekn ik/article/download/90/127, tanggal akses 12 September 2016.

PemodelanKekuatan Sinyal Wireless Dengan Metode Finite Difference Time Domain, http://ojs.amikom.ac.id/index.php/semnast eknomedia/article/viewFile/530/507, tanggal akses 23 Mei 2016.

Pratama I Putu Agus Eka .(2014). Handbook Jaringan Komputer.Informatika. Bandung
Prayadi, Fendi, Khairul Imtihan, and Hairul Fahmi. "Sistem Informasi Monitoring Data Debit Daerah Irigasi Dengan Metode Pengukuran Debit Sesaat (Studi Kasus: Bendungan Batujai Kecamatan Praya Barat Kabupaten Lombok Tengah, NTB)." Jurnal Manajemen Informatika dan Sistem Informasi 1.1 (2018): 39-45.

Rudi Hidayat, Nana Juhana, \& Deden Suryana. (2004). Teknologi Informasi dan Komunikasi. PT. Gelora Aksara Pratama : Erlangga

Utomo. E. P. 2011. Membangun Jaringan Komputer dan Server Internet (Untuk Jaringan Rumahan, Warnet dan Kantor).Yogyakarta.MediaKom.

Khairul Imtihan. "Perencanaan Strategi Sistem Informasi Pendidikan Pada Sekolah Tinggi Manajemen Informatika dan Komputer (STMIK) Lombok." Bianglala Informatika 3.2 (2015).

Kalaena, Lalu Supriadi, and Wire Bagye. "Implementasi Network Attached Storage (NAS) Menggunakan Freenas Pada STMIK Lombok." Jurnal Manajemen Informatika dan Sistem Informasi 1.1 (2018): 6-10. 